\title{
Poxviruses: smallpox vaccine, its complications and chemotherapy
}

\author{
This article was published in the following Dove Press journal: \\ Virus Adaptation and Treatment \\ 16 April 2010 \\ Number of times this article has been viewed
}

\section{Mimi Remichkova \\ Department of Pathogenic Bacteria, The Stephan Angeloff Institute of Microbiology, Bulgarian Academy of Sciences, Sofia, Bulgaria}

\begin{abstract}
The threat of bioterrorism in the recent years has once again posed to mankind the unresolved problems of contagious diseases, well forgotten in the past. Smallpox (variola) is among the most dangerous and highly contagious viral infections affecting humans. The last natural case in Somalia marked the end of a successful World Health Organization campaign for smallpox eradication by vaccination on worldwide scale. Smallpox virus still exists today in some laboratories, specially designated for that purpose. The contemporary response in the treatment of the post-vaccine complications, which would occur upon enforcing new programs for mass-scale smallpox immunization, includes application of effective chemotherapeutics and their combinations. The goals are to provide the highest possible level of protection and safety of the population in case of eventual terrorist attack. This review describes the characteristic features of the poxviruses, smallpox vaccination, its adverse reactions, and poxvirus chemotherapy.

Keywords: poxvirus, smallpox vaccine, post vaccine complications, inhibitors
\end{abstract}

\section{Characteristics of poxviruses}

Smallpox (variola) infection is caused by the smallpox virus. This virus belongs to the genus of Orthopoxvirus included in the Poxviridae family. Poxviruses are one of the largest and most complexly structured viruses, known so far. The genome of poxviruses consists of a linear two-chained DNA and its replication takes place in the cytoplasm of the infected cell. It has been shown that two distinct forms of infectious virions are produced in poxvirus-infected cells: intracellular mature virus (IMV), which is released only following death and lysis of infected cells, and extracellular-enveloped virus (EEV), which is actively extruded from cells by interaction with actin tails. The release of EEV from infected cells is thought to be the principal mechanism for rapid spread of the virus in the infected host. ${ }^{1}$

Poxviruses provide some of the most extensive inventories of gene products that serve to defend these viruses against the aggressive assault executed by the host immune response. Cell-mediated immunity (CMI) components of the vertebrates also participate in the host response to infection. Different types of innate effector cells, such as natural killer (NK) cells, and educated effector cells, such as cytotoxic T lymphocytes (CTLs) rapidly identify and eliminate infected cells before the virus can replicate and spread. Poxviruses utilize strategies to modify host pathways that regulate the earliest aspects of immune responses, particularly the interferons (IFNs), the chemokines, the pro-inflammatory cytokines (interleukin [IL]-1, tumor necrosis factor [TNF], IL-18), complement, and the regulatory components that orchestrate cellular immunity and apoptosis. ${ }^{2-4}$ They affect all vertebrates, including man, but also some invertebrates,
Correspondence: Mimi Remichkova The Stephan Angeloff Institute of Microbiology, Bulgarian Academy of Sciences, 26, Acad. Georgi Bonchev Str. III 3 Sofia, Bulgaria

Tel +35929793161

Fax +35928700109

Email mremichkova@gmail.com 
predominantly insects and arthropods. ${ }^{5}$ Poxviruses of several groups infect man: smallpox (variola), vaccinia virus, monkeypox, cowpox, orf virus, milkers nodes, molluscum contagiosum (Table 1). ${ }^{6-9}$ Monkeypox virus is considered to be the most important orthopoxvirus infection in humans. The virus can cause disease clinically indistinguishable from smallpox. Epidemiologic data led to the conclusion that monkeypox virus causes a sporadic disease with a low potential for person-toperson transmission and that infection could not sustain itself in the human population. ${ }^{10}$ Although monkeypox virus is the only known severe orthopoxvirus infection today, the current dynamics of monkeypox virus infection are poorly understood and little information is available to improve World Health Organization (WHO) recommendations for the prevention of human monkeypox virus.

Poxviruses possess complex antigen nature. Their specific cross-reacting antibodies allow vaccination with less hazardous virus. Thus vaccinia virus for smallpox immunization could be used. ${ }^{11,12}$

\section{Smallpox infection}

Smallpox infection causes respiratory symptoms and a variety of clinical symptoms, among which the typical pox pustule on the skin and internal organs, raised body temperature and overall weakness. ${ }^{13,14}$ In principle, the spread of smallpox takes place via direct man-to-man contact, by drops from the salivary glands or respiratory secretions. The incubation period has a constant duration of 12 days for the preceding viremic stage and 14 days for the typical burst of eruption. Smallpox has the nature of acute infection. The preceding symptoms during the first 2-4 days include back pain, fever and prostration. Delirium and coma may also occur. The virus is spread by the mucose membrane of the lymph nodes, subsequently causing viremia. Typical scars remain after this decease. More severe forms of smallpox can cause tumor genesis, necrosis, injury of the central nervous system and

Table I Poxviruses affecting humans

\begin{tabular}{ll}
\hline Genus & Virus \\
\hline Orthopoxvirus & Smallpox (variola) \\
& Vaccinia \\
& Monkeypox \\
& Cowpox \\
Parapoxvirus & Orf \\
Molluscipoxvirus & Milker's nodes \\
\hline
\end{tabular}

even death (Table 2). ${ }^{15}$ Such symptoms have been observed when vaccinia virus is injected into risky hosts., ${ }^{9,16}$

\section{Smallpox vaccine}

In 1796 the English doctor Edward Jenner succeeded in preventing the development of smallpox in the 8-year-old James Phipps by inoculation of contagious material from infected cows. A month and a half later he checked the vaccine effectiveness by injecting live smallpox virus into the boy, who stayed fully protected and did not develop any symptoms of the disease. Jenner introduced the vaccination as a method of immunization. ${ }^{17}$ The traditional variola vaccine is live vaccine from calves: Dryvax. Another type of traditional vaccine is tissue or cell type cultural vaccine, using vaccinia virus, which is comparatively non-virulent. These vaccines are not applicable in immunocompromised humans. They can cause severe complications in some of the cases. ${ }^{16,18,19}$ Due to the ability of poxviruses to acquire foreign genetic material, the possibility to apply these viruses as vectors for production of recombinant vaccines for various diseases in humans and animals, as well as in gene therapy is under serious research. ${ }^{20,21}$

It was shown that vigorous and long-lasting protective immune responses associated with smallpox vaccination, and specific immunity, is believed to be maintained for decades. Memory B cells are likely to be important players in human immunity to smallpox, both by their ability to rapidly respond to infection with an anamnestic $\mathrm{Ab}$ response and by their potential ability to replenish long-lived plasma cells to maintain long-term Ab levels. ${ }^{22}$ Vaccinia virus-specific memory $\mathrm{T}$ cells are also likely to be critical components of the vaccine-madiated protection against smallpox virus and the smallpox vaccine is known to elisit $\mathrm{T}$ cell responcees. Data showed that Ag-specific B and T cell memory are both present for multiple decades after vaccination and that these lymphocyte populations are independently regulated, since they exhibit distinct decay kinetics. ${ }^{23,24}$

The need to reduce the potential for serious systemic adverse events associated with replication-competent vaccinia has led to renewed interest in attenuated strains such as modified vaccinia Ankara (MVA), particularly in populations with compromised immune systems. MVA, an attenuated

Table 2 Smallpox (variola) subtypes

\begin{tabular}{ll}
\hline Smallpox subtypes & Mortality (\%) \\
\hline Variola major & $25-30$ \\
Variola minor (alastrim) & $<1$ \\
\hline
\end{tabular}


derivative of dermal chorioallantois vaccinia strain Ankara (CVA), was registered in Germany in 1976. MVA was effective in animal variola challenge models and protected monkeys against a lethal monkeypox challenge ${ }^{25-28} \mathrm{LC} 16 \mathrm{~m} 8$, an attenuated, replicating smallpox vaccine derived from the Lister strain of vaccinia, is currently licensed in Japan where it was safely used in over 50,000 children in the 1970 s. It has been shown to have markedly less neurotoxicity than unattenuated vaccines in non-clinical studies. ${ }^{29,30}$ Currently available vaccines will probably protect against the naturally occurring viruses, such as monkeypox, cowpox, and vaccinia viruses as they evolve, but they might not protect against certain genetically engineered viruses.

As a result of widescale application of variola vaccine for a period of two full centuries, the disease has been eliminated worldwide. The last incidence was recorded in Somalia in October 1977..$^{31}$ On May 8th, the WHO declared the eradication of smallpox worldwide. Gradually vaccination has been terminated: in Europe in 1980, in Africa in 1982, and in America in 1983. In some countries vaccination was continued for military contingents until 1995. ${ }^{32,33}$ Eradication of smallpox has become possible because there is no extrahuman reservoir for the virus. Inapparent infections and chronic carriers of the virus do not exist and the incubation period of 12 to 14 days allows time for interventive immunization (Table 3) ${ }^{34}$ As a result, the smallpox virus can now be found only in laboratories such as those in Atlanta, Georgia, USA and Novosibirsk, Siberia, Russia.

\section{Smallpox vaccine complications}

With the emerging risk of a biological threat, smallpox is ranked high in the list of agents which could be used for bioterrorism. The only safe and effective method of prevention is immunization against smallpox. This necessitates the production of the vaccine and subjecting certain groups of the population to smallpox immunization. As previously

Table 3 Biological features of smallpox that contributed to its eradication

Severe disease

No subclinical cases

Infectivity accompanies rash

Recurrent infectivity unknown

Only one serotype

Availability of an effective stable vaccine

Seasonality

No animal reservoir mentioned, for some individuals the smallpox immunization may result in side effects and adverse reactions. On the whole, all of these are fully benign, yet their occurrence is a serious and alarming sign. Some are serious, yet fully curable. Others, having a very low frequency, are life-threatening and may have fatal outcome. ${ }^{35}$ The majority of the information concerning adverse reactions came from the American Red Cross vaccinia immune globulin (VIG) distribution system. The strain of vaccinia virus might correlate with the type and frequency of adverse reactions. ${ }^{34}$ All US preparations of smallpox vaccine contain the $\mathrm{NYCBOH}$ strain, one of the less reactogenic strains. Therefore, the US experience might not represent international experience, which reflects use of other vaccinia strains. Virulence of vaccinia strain is associated with risk for post-infectious encephalitis, as well as the likelihood of contact transmission. Since the vaccine has not been applied after 1980 a large number of the world's civilion population is faced with the threat of being infected in the case of a potential epidemic. So once again mankind faces its old unresolved problem - the smallpox vaccine complications, some of which are quite serious and may have a lethal outcome. ${ }^{36-39}$ The post-vaccination complications can be classified in several categories:

\section{Progressing vaccine reaction (vaccinia necrosis, vaccinia gangrenosum)}

Vaccine reaction is the most serious complication, occurring after smallpox immunization. ${ }^{40,41}$ It occurs when people with immune deficiency have been immunized. The disease has a quite insidious character. In the beginning the lesion takes the form of a normal vaccine reaction, yet it continues its evident progression and for lethal cases does not reveal any signs of possible regression.

\section{Post-vaccine eczema (eczema vaccinatum)}

The vaccine type eczema represents a local or generalized dissemination of vaccinia virus. ${ }^{42}$ In immunocompromised patients, eczema with fatal outcome has been observed. ${ }^{41}$

\section{Generalized vaccine reaction (vaccinia generalisatum)}

The generalized vaccine reaction is characterized by vesicles or pustules on preliminarily not injured skin at a distance from the place of the immunization. This skin reaction is due to viremia of the vaccine virus. ${ }^{38,43}$ In general, the majority of all vaccine reactions, including vaccinia generalisatum, 
are accompanied by mildly manifested common symptoms and bring about insignificant residual events. However, in persons with immunodeficiencies the generalized vaccine reaction may take the form of significant total intoxication. ${ }^{44,45}$

Different bibliographic resources list other smallpox immunization complications, such as: erythemic and urtical eruptions, post-vaccine keratitis, post-infectious encephalitis and meningoencephalitis. Sporadic cases of myocarditis, thrombocytopenia, arthritis and pericarditis have also been reported. $^{46}$

\section{Chemotherapy of poxviruses}

In view of the potential menace of terrorism attack with smallpox virus, as well as the necessity for treatment of the post-vaccine stage complications, which would occur in the case of applying the new programs for mass scale smallpox immunization, there is a strong focus on an intensive search for chemotherapeutic agents active against poxviruses. During recent years inhibitors of poxviruses replication have been subject to serious research with the objective of limiting the seriousness of viral infections in humans and animals.

Irrespective of the smallpox eradication, infections by other agents, representatives of poxviruses, are among the most serious threats to human health. The monkeypox virus can infect humans and occasional cases have been reported in equatorial Africa. ${ }^{47}$ Molluscum contagiosum most commonly affects young children, but it often occurs in immunocompromised patients. ${ }^{48,49}$ The smallpox virus (Variola major) is ranked very highly as a potential agent for bioterrorism. Although smallpox eradication is a fact, all physicians must be familiar with this disease due to its potential to spread rapidly.

Poxviruses encode a large number of enzymes, including DNA polymerase and thymidine kinase, which are of potential interest as targets for antiviral compounds. The first compound described in the literature was $p$-aminobenzaldehyde thiosemicarbazone, which Brownlee and Hamre $^{50}$ established inhibited the replication of vaccinia virus. Bauer and Sadler ${ }^{51}$ found that 1-methyl-1H-indole2,3-dione-3-thiosemicarbabazone (methisazone, Marboran ${ }^{\circledR}$ ) manifested a prophylactic and not a therapeutic effect against smallpox. Later, Borysiewicz and colleagues ${ }^{52}$ found a comparatively low selectivity ratio value for 1 -methyl-1Hindole-2, 3-dione-3-thiosemicarbazone based on its marked immunotoxicity. Among compounds showing anti-poxvirus activity are idoxuridine, ribavirin, cidofovir, interferon and polyacrylic acid. ${ }^{53}$
Cidofovir is an antiviral drug, recommended by the WHO for treatment of smallpox and heavy post-smallpox vaccination reactions. Cidofovir is an acyclic nucleoside phosphonate licensed for the treatment of cytomegalovirus retinitis in AIDS patients. Cidofovir is very effective in vitro against poxviruses: vaccinia virus, cowpox, monkeypox, camelpox and smallpox viruses. ${ }^{54}$ It has been shown to strongly inhibit orthopoxvirus infections in vivo, including cowpox virus infection when prescribed as a combined treatment with ribavirin. ${ }^{55}$ More recently, cidofovir has been approved for the treatment of Molluscum contagiosum and orf infections in humans, and has demonstrated a marked protective effect in variola and monkeypox. ${ }^{56}$ However, cidofovir is not orally bioavailable, and its use can be associated with significant nephrotoxicity and hematological toxicity. ${ }^{57}$

A series of lipid-ester derivatives of cidofovir has been developed that decrease toxicity by reducing kidney exposure to the drug and increase oral bioavailability. Hexadecyloxypropylcidofovir (CMX001) is one of these new derivatives. Its bioavailability and cellular uptake are significantly enhanced because of the lipid moiety, which is cleaved inside the cell by phospholipase to liberate cidofovir. This increased cellular uptake of CMX001 results in enhanced activity compared with cidofovir against multiple double-strand DNA viruses, including poxvirus and cytomegalovirus infections. ST-246 is a small-molecule, potent pharmacological inhibitor of orthopoxvirus dissemination. ST-246 targets CMX001 and ST-246 are the only anti-poxvirus drugs currently in clinical trial. Synergistic combination of ST-246 and CMX001 appears promising against orthopoxviruses. ${ }^{58,59}$ In the search for more effective therapy against poxviruses infections the combined effect of cidofovir and idoxuridine to the replication of the Bratislava strain of virus vaccinia was studied. The data demonstrated clearly defined synergy of the antivirus effect of the combination of cidofovir and idoxuridine, with antagonism of the combined cytotoxicity in a growing and monolayer cell culture. ${ }^{60}$ Other compounds are approved for the treatment of poxviruses. The acyclic nucleoside phosphonate drug (S)-9-[3-hydroxy-(2-phosphonomethoxy) propyl]adenine ((S)-HPMPA) is a highly effective inhibitor of vaccinia virus DNA polymerase when incorporated into the template strand. ${ }^{61} \mathrm{~N}$-Methanocarbathymidine ((N)-MCT) and SRI 21950 (4'-thio derivative of iododeoxyuridine) are newly identified inhibitors of orthopoxvirus replication in cell culture and in mice. ${ }^{62,63}$ Vaccinia virus p37 (VV p37) has been shown to inhibit plaque formation in vitro and prevent systemic viral spread in vivo indicating that the compound inhibits the release of extracellular virus. ${ }^{64}$ The achieved 
results are sound preconditions for a broader study of the impact of a number of substances with demonstrated antiviral activity against poxviruses.

Early studies indicated that the complications of smallpox vaccine administration appeared to occur soon after vaccination can often be managed with VIG. ${ }^{65,66}$ VIG may also be needed as prophylaxis in patients for whom pre-exposure smallpox vaccine is contraindicated (such as those with eczema or pregnant women), although it is currently not licensed in these cases. VIG is an immune globulin made from the blood of people who have received the smallpox vaccine more than once (usually many times). Two intravenous formulations of VIG (VIGIV, Cangene; VIGIV, DynPort) have been licensed for the management of patients with progressive vaccinia, eczema vaccinatum, severe generalized vaccinia, and extensive body surface involvement or periocular implantation following inadvertent inoculation. ${ }^{67,68}$

As an alternative, post-exposure vaccination could be an important countermeasure to be implemented after an eventual bioterrorist attack using the causative agent, variola virus. Analyses of some studies showed that post-exposure vaccination immediately after exposure might protect against disease. ${ }^{69,70}$

\section{Conclusion}

Irrespective of the global eradication of smallpox, which has resulted in the suspension of vaccination, the possibility still exists for smallpox virus to be used for bioterrorism. The analysis of both the accomplishments and failures in application of smallpox vaccine demonstrates the need for more comprehensive study on the pathogenesis of the infections caused by poxviruses. The necessity for resuming the search for inhibitors, active against poxviruses, is evident. Expanding the research by studying the effect of combinations of well-known antivirus inhibitors having differents modes of action would facilitate the development of a more effective therapy for poxvirus virus infections.

\section{Disclosure}

The author reports no conflicts of interest in this work.

\section{References}

1. Smith GL, Law M. The exit of Vaccinia virus from infected cells. Virus Res. 2004;106:189-197.

2. Barry M, McFadden G. Virus encoded cytokines and cytokine receptors. Parasitology. 1997;115:S89-S100.

3. Alcam IA, Koszinowski UH. Viral mechanisms of immune evasion. Immunol Today. 2000;21:447-455.

4. McFadden G, Murphy PM. Hostrelated immunomodulators encoded by poxviruses and herpesviruses. Curr Opin Microbiol. 2000;3:371-378.

5. Granados RR. Entry of an insect poxvirus by fusion of the virus envelope with the host cell membrane. Virology. 1973;52:305-309.
6. Antoniou C, Kosmadaki MG, Stratigos AJ, et al. Genital HPV lesions and molluscum contagiosum occurring in patients receiving anti-TNFalpha therapy. Dermatology. 2008;216:364-365.

7. Hwang YB, Wang B, Bushman FD, et al. Molluscum contagiosum virus topoisomerase: purification, activities and response to inhibitors. JVirol. 1998;72:3401-3406.

8. Strenger V, Müller M, Richter S, et al. A seventeen-year-old girl with a black eschar. Cowpox virus infection. Clin Infect Dis. 2009;48:91-92, 133-134.

9. Trindade GS, Guedes MI, Drumond BP, et al. Zoonotic vaccinia virus: clinical and immunological characteristics in a naturally infected patient. Clin Infect Dis. 2009;48:37-40.

10. Rimoin AW, Kisalu N, Kebela-Ilunga B, et al. Endemic human monkeypox, Democratic Republic of Congo, 2001-2004. Emerg Infect Dis. 2007;13:934-937.

11. Esposito JJ, Obijeski JF, Nakano JH, et al. Orthopoxvirus DNA: Strain differentiation by electrophoresis of restriction endonuclease fragment virion DNA. Virology. 1978;89:53-66.

12. Harper L, Bedson HS, Buchan A, et al. Identification of orthopoxviruses by polyacrylamide gel electrophoresis of intracellular polypeptides. I. Four major groupings. Virology. 1979;93:435-444.

13. Goebel SJ, Jonson GP, Perkus ME, et al. The complete DNA sequence of vaccinia virus. Virology. 1990;179:247-266, 517-563.

14. Lane JM, Millar JM, Neff JM, et al. Smallpox and smallpox vaccination policy. Ann Rev Med. 1972;22:251.

15. Graham CL. Poxvirus infection in a spectacled Amazon parrot (Amazona albifrons). Avian Dis. 1978;22:340-343.

16. Henderson DA. Smallpox: clinical and epidemiologic features. Emerg Infect Dis. 1999;5:537-539.

17. Tan SY. Medicine in stamps. Edward Jenner (1749-1823): conqueror of smallpox. Singapore Med J. 2004;45:507.

18. Newman FK, Frey SE, Blevins TP, et al. Improved assay to detect neutralizing antibody following vaccination with diluted or undiluted

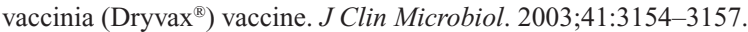

19. Turner GS, Squires EJ, Murray HG, et al. Inactivated smallpox vaccine. A comparison of inactivation methods. J Hyg (Lond). 1970;68:197-210.

20. Heraud JM, Edghill-Smith Y, Ayala V, et al. Subunit recombinant vaccine protects against monkeypox. J Immunol. 2006;177:2552-2564.

21. Sakhatskyy P, Wang S, Zhang C, et al. Immunogenicity and protection efficacy of subunit-based smallpox vaccines using variola major antigens. Virology. 2008;371:98-107.

22. Crotty S, Felgner P, Davies H, Glidewell J, Villarreal L, Ahmed R. Cutting edge: Long-term B cell memory in humans after smallpox vaccination. J Immun. 2003;171:4969-4973.

23. Ennis FA, Cruz J, Demkowicz WE, Rothman AL, McClain DJ. Primary induction of human $\mathrm{CD} 8^{+}$cytotoxic $\mathrm{T}$ lymphocytes and interferon- $\gamma$-producing $\mathrm{T}$ cells after smallpox vaccination. $J$ Infect Dis. 2002; 185:1657.

24. Poccia F, Gioia C, Montesano C, et al. Flow cytometry and T-cell response monitoring after smallpox vaccination. Emerg Infect Dis. 2003;9:1468-1470.

25. Earl PL, Americo JL, Wyatt LS, et al. Immunogenicity of a highly attenuated MVA smallpox vaccine and protection against monkeypox. Nature. 2004;28:182-185.

26. Hochstein-Mintzel V, Hanichen T, Huber HC, et al. An attenuated strain of vaccinia virus (MVA). Successful intramuscular immunization against vaccinia and variola. Zentralbl Bakteriol. 1975;230:283-297.

27. Mayr A, Stickl H, Müller HK, et al. The smallpox vaccination strain MVA: marker, genetic structure, experience gained with the parenteral vaccination and behavior in organisms with a debilitated defense mechanism. Zentralbl Bakteriol. 1978;167:375-390.

28. Stickl H, Hochstein-Mintzel V, Mayr A, et al. MVA-vaccination against smallpox: clinical trials of an attenuated live vaccinia virus strain (MVA). Dtsch Med Wschr. 1974;99:2386-2392.

29. Hashizume S, Yoshizawa H, Morita M, et al. Properties of attenuated mutant of vaccinia virus, LC16m8, derived from Lister strain, In: Quinnan $\mathrm{GV}$, editor. Vaccinia viruses as vectors for vaccine antigens. Amsterdam, The Netherlands: Elsevier; 1985. pp. 88-99. 
30. Kenner J, Cameron F, Empig C, et al. LC16m8: an attenuated smallpox vaccine. Vaccine. 2006;24:7009-7022.

31. Deria A, Jezek Z, Carrasco P, et al. The world's last endemic case of smallpox: surveillance and containment measures. Bull World Health Organ. 1980;58:279-283.

32. World Health Organization. Technical Report, Series No 323. WHO Expert Group on Requirements for Biological Substances. Geneva, Switzerland: World Health Organization: 1966.

33. World Health Organization. Technical Report, Series No 492, WHO Expert Committee on Smallpox Eradication, Second Report. Geneva, Switzerland: World Health Organization: 1972.

34. Fenner F, Henderson DA, Arita I, et al. Smallpox and its eradication. Geneva, Switzerland: World Health Organization Press; 1988.

35. Sarkar JK, Mitra AC, Mukherjee MK. The minimum protective level of antibodies in smallpox. Bull World Health Organ. 1975;52:307-311.

36. Casey C, Vellozzi C, Mootrey GT, et al. Surveillance guidelines for smallpox vaccine (vaccinia) adverse reactions. MMWR Recomm Rep. 2006;55:1-16

37. Neff JM, Lane JM, Pert JH, Moore R, Millar JD, Henderson DA. Complications of smallpox vaccination. National survey in the United States, 1963. N Engl J Med. 1967;276:125-132.

38. Lane JM, Ruben FL, Neff JM, et al. Complications of smallpox vaccination. $N$ Engl J Med. 1968;281:1201-1208.

39. Lane JM, Ruben FL, Neff JM, et al. Complications of smallpox vaccination, 1968: results of 10 state-wide surveys. J Infect Dis. 1970; 122:303-309.

40. Neff JM, Lane JM. Vaccinia necrosum following smallpox vaccination for chronic herpetic ulcers. JAMA. 1970;213:123-125.

41. Neff JM, Drachman. RH. Complications of smallpox vaccination. 1968: Surveillance in a comprehensive care clinic. Pediatrics. 1972;50:481-483.

42. Copeman PWM, Wallace HJ. Eczema vaccinatum. Br Med J. 1964;2:906-908.

43. Polak MF. Complication of smallpox vaccination in the Netherlands 1959-1970. Int Symp Smallpox Vaccine Bilthoven. 1972;19:235.

44. Halsey NA, Henderson DA. HIV infection and immunization against other agents. $N$ Engl J Med. 1987;316:683-685.

45. Keidan SE, McCarthy K, Haworth JC. Fatal generalized vaccinia with failure of antibody production and absence of serum gamma globulin. Arch Dis Child. 1953;28:110-116.

46. Marcus L. Israel's preparedness for responding to the health requirements of its civilian population in the evant of deployment of a nuclear, biological or chemical weapon of mass destruction. A report on meetings and interviews, 27 October, 2002. Available at www.calhealthofficers. org/Documents/Marcus_Israel_WMD_Report.doc.

47. Heiner GG, Fatima V, Russell PK, et al. Field trials of methisazone as a prophylactic agent against smallpox. Am J Epidemiol. 1971;94:435-449.

48. Coloe J, Morrell DS. Cantharidin use among pediatric dermatologists in the treatment of molluscum contagiosum. Pediatr Dermatol. 2009;26:405-408.

49. Bachmeyer C, Moguelet P, Baud F, et al. Efflorescence of facial molluscum contagiosum as a manifestation of immune reconstitution inflammatory syndrome in a patient with AIDS. Eur J Dermatol. 2009;19: 257-258.

50. Brownlee KA, Hamre D. Studies on chemotherapy of vaccinia virus. I. An experimental desin for testing antiviral agents. J Bacteriol. 1951; 61:127-134.
51. Bauer DJ, Sandler PW. The structure-activity relationships of the antiviral chemotherapeutic activity of isantin $\beta$-thiosemikarbazone. $\mathrm{Br} J$ Pharmacol. 1960;15:101-110.

52. Borysiewicz T, Mizerski T, Pryma T. Effect of methisazone on immune response in mice. Chemotherapy. 1977;23:276-281.

53. De Clercq E. Vaccinia virus inhibitors as a paradigm for the chemotherapy of poxvirus infections. Clin Microbiol Rev. 2001;14:382-397.

54. Kern ER, Hartline C, Harden E, et al. Enhanced inhibition of orthopoxvirus replication in vitro by alkoxyalcyl esters of cidofovir and cyclic cidofovir. Antimicrob Agents Chemother. 2002;46:991-995.

55. Smee DF, Baily KW, Sidwell RW. Treatment of cowpox virus respiratory infections in mice with ribavirin as a single agent or followed sequentially by cidofovir. Antivir Chem Chemother. 2000;11:303-309.

56. Huggins JW, Martinez MJ, Hartmann CJ, et al. Successful cidofovir treatment of smallpoxlike disease in variola and monkeypox primate models. Antiviral Res. 2004;62:A76.

57. Plosker GL, Noble S. Cidofovir - a review of its use in cytomegalovirus retinitis in patients with AIDS. Drugs. 1999;58:325-345.

58. Quenelle DC, Prichard MN, Keith KA, et al. Synergistic efficacy of the combination of ST-246 with CMX001 against orthopoxviruses. Antimicrob Agents Chemother. 2007;51:4118-4124.

59. Yang G, Pevear DC, Davies MH, et al. An orally bioavailable antipoxvirus compound (ST-246) inhibits extracellular virus formation and protects mice from lethal orthopoxvirus Challenge. J Virol. 2005; 79:13139-13149.

60. Remichkova M, Petrov N, Galabov AS. Synergistic combination effect of cidofovir and idoxuridine on vaccinia virus replication. Antivir Chem Chemother. 2006:17:53-58

61. Magee WC, Aldern KA, Hostetler KY. Cidofovir and (S)-9-[3-hydroxy(2-phosphonomethoxy)propyl]adenine are highly effective inhibitors of vaccinia virus DNA polymerase when incorporated into the template strand. Antimicrob Agents Chemother. 2008;52:586-597.

62. Smee DF. Progress in the discovery of compounds inhibiting orthopoxviruses in animal models. Antivir Chem Chemother. 2008;19:115-124.

63. Smee DF, Hurst BL, Wong MH, et al. Efficacy of N-methanocarbathymidine in treating mice infected intranasally with the IHD and WR strains of vaccinia virus. Antiviral Res. 2007;76:124-129.

64. Chen Y, Honeychurch KM, Yang G, et al. Vaccinia virus p37 interacts with host proteins associated with LE-derived transport vesicle biogenesis. Virol J. 2009;6:44.

65. Kempe $\mathrm{CH}$, Bowles $\mathrm{C}$, Meiklejohn T, et al. The use of vaccinia hyperimmune gamma-globulin in the prophylaxis of smallpox. Bull World Health Org. 1961;25:41-48.

66. Pierce LR, Jain N. Risks associated with the use of intravenous immunoglobulin. Transfus Med Rev. 2003;17:241-251.

67. Seth V, Malaviya AN, Gopalan PR, Ghai OP. Progressive vaccinia successfully treated with vaccinia immune globulin. Indian Pediatrics. 1978; 15:67-72.

68. Wittek R. Vaccinia immune globulin: current policies, preparedness, and product safety and efficacy. Int J Infect Dis. 2006;10:193-201.

69. Mortimer PP. Can postexposure vaccination against smallpox succeed? Clin Infect Dis. 2003;36:622-629.

70. Nishiuraa H, Eichnera M. Interpreting the epidemiology of postexposure vaccination against smallpox. Int J Hyg Environ Health. 2008;211:219-226.
Virus Adaptation and Treatment

\section{Publish your work in this journal}

Virus Adaptation and Treatment is an international, peer-reviewed open access journal focusing on the study of virology, viral adaptation and the development and use of antiviral drugs and vaccines to achieve improved outcomes in infection control and treatment. The journal welcomes original research, basic science, clinical \& epidemiological

\section{Dovepress}

studies, reviews \& evaluations, expert opinion and commentary, case reports and extended reports. The manuscript management system is completely online and includes a very quick and fair peer-review system, which is all easy to use. Visit http://www.dovepress.com/ testimonials.php to read real quotes from published authors. 